\title{
Production of pyroligneous acid from lignocellulosic biomass and their effectiveness against biological attacks
}

\begin{abstract}
Pyroligneous acid which is one of the commercial sources for acetic acid can be produced from high temperature carbonization of lignocellulosic biomass. Acetic acid can be used as a wood preservative to discourage the growth of fungal and molds. However, at higher temperature, organic compounds especially acetic acid in pyroligneous acid degraded except for some phenols. Therefore, effectiveness pyroligneous acid that pyrolysed at different temperature as fungicide and insecticide for used as wood preservative was evaluated. Pyroligneous acids were derived from rubberwood, oil palm trunk and mix hardwood heated at temperature of 300,400 and $500^{\circ} \mathrm{C}$, respectively in an airless container. The yield of pyroligneous acids was calculated and the chemical compounds of the pyroligneous acid were analysed using Fourier Transform InfraRed (FT-IR). For the efficacy of pyroligneous acid tests, rubberwood test blocks were immersed in the pyroligneous acid for $24 \mathrm{~h}$ at room temperature. The treated rubberwood test blocks were later tested against mold (Penicillium sp.), white rot fungus (Pycnoporous sanguineus) and subterranean termites, (Coptotermes curvignathus) according to ASTM standard method. The result shows that highest pyroligneous acid yield was found during pyrolysed of lignocellulosic biomass at temperature of $500^{\circ} \mathrm{C}$. All the rubberwood test blocks treated with pyroligneous acids were effective against the mold, white rot fungi and termites. Nonetheless, the pyrolysis temperature did not affect the effectiveness of pyroligneous acids against biological agents. Conclusively, pyroligneous acids effective for discourage the growth of mold and white rot fungi as well accelerate the mortality of termites in laboratory condition.
\end{abstract}

Keyword: Pyroligneous acid; Termites; Oil palm trunk; Mold; Decay fungi 